\title{
Role of Magnetic Resonance Imaging (MRI) and Magnetic Resonance Spectroscopy (MRS) in Differentiating Post Therapeutic Changes from Recurrent Malignant Breast Lesions
}

\author{
MAI F. MOHAMED, M.Sc.; HOSSAM ABD EL-KADER, M.D. and AHMED M. EL-CHIMY, M.D. \\ The Department of Radiology, Faculty of Medicine, Ain Shams University
}

\begin{abstract}
Background: Patients follow-up subsequent to conservative breast therapy (BCT) is essential due to tumor recurrence with rates ranging between $1 \%$ and $2 \%$ annually. It occurs commonly during a period of 3-7 years after being subjected to BCT. Timely and early detection of breast cancer recurrence is believed to remarkably improve and assist long-term survival.

Aim of Study: To assess new advances of Magnetic Resonance Imaging (MRI) and Magnetic Resonance Spectroscopy (MRS) in diagnosis of recurrent breast cancer after conservative surgery, chemotherapy and radiotherapy and differentiate it from post therapeutic changes.
\end{abstract}

Patients and Methods: The current study was conducted on 20 patients proved to be breast carcinoma by histopathological grading. Six patients were presented with breast lump, three patients were presented by nipple discharge, four patients were presented by diffuse breast enlargement and seven patients were presented for post-operative follow-up at ElDemerdash Hospital during the period from October 2018 to April 2019.

Results: A strong positive correlation is detected between choline peak findings and the level of Ki67, the higher the choline the higher the Ki67 the more aggressiveness is the tumor.

Conclusion: Both dynamic contrast enhanced MRI and MRS are valuable tools in the evaluation of post-operative breast having high sensitivity and specificity to differentiate between benign post-operative changes and recurrent malignant tumor. On the other hand, MRI on the breast can assist to avoid unnecessary interventions and optimizes diagnosis of recurrence in its early stages.

Key Words: Magnetic resonance imaging - Magnetic resonance spectroscopy - Malignant breast lesions.

\section{Introduction}

CHANGES on both physical examination and post treatment breast imaging occur after conservative

Correspondence to: Dr. Mai F. Mohamed, The Department of Radiology, Faculty of Medicine, Ain Shams University breast surgery followed by breast radiotherapy. It is usually difficult to detect local tumor recurrence, as well as evaluation of the remainder of the breast tissue depending on conventional techniques; since post-treatment alteration, especially within dense breasts; hence, taking repeated biopsy is often required [1].

Breast conservative surgeries target first surgical excision of the breast tumors with a surrounding margin of histologically normal breast parenchyma while conserving the patient's breast appearance and form. Breast conservative surgery is the most common surgical option for patients with early stages of breast cancer, namely $\mathrm{T} 1$ or T2 [2]

Chemotherapy may result in fibrosis and necrosis, in the shape of permanent thickness on mammogram. Similarly, calcifications noted in carcinoma can be durable even after disappearance of viable tumor cells. Both permanent shapes and calcification can be misdiagnosed as carcinoma on mammogram, leading to false positive outcomes [3].

DCE-MRI has a vital role in detection and identification of both primary and recurrent breast tumors. MRI sensitivity of breast for detection of residual and recurrent tumors in the post-operative breast exceeds $90 \%$. Breast MR imaging has been shown to be useful in differentiating scar tissue from tumor recurrence regarding the non-enhancing areas with high Negative Predictive Value (NPV) for malignancy (88-96\%) [4]

It is also a valuable technique and more specific in distinction between changes following irradiation and recurrent carcinoma in patients who had undergone breast irradiation [3]. 
Magnetic resonance spectroscopy is used now as an adjacent modality added to Dynamic Contrast Enhanced MRI (DCE-MRI) in practical and clinical evaluations of breast cancer. Malignant lesions are considered as a marker of high levels of cholinecontaining compounds compared to benign or totally normal breast tissues. An observation which may serve as the basis for differentiating between malignant and benign breast tumor. DCE-MRI together with MR spectroscopy enables the highly accurate sort of assessment of tumor response in cases with breast cancer after Neoadjuvant Chemotherapy (NAC) compared with other routine methods; as it can observe and monitor full, partial and poor responses [5].

\section{Aim of the study:}

The purpose of our study is evaluation of the new advances of magnetic resonance imaging and magnetic resonance spectroscopy in diagnosing recurrent breast cancer after conservative surgery, chemotherapy and radiotherapy and differentiate it from post therapeutic changes.

\section{Patients and Methods}

This study involved 20 patients proved to be breast carcinoma by histo-pathological grading their mean age was 43 years old female (age range, 25-60 years). Six patients were presented with breast lump, three patients were presented by nipple discharge, four patients were presented by diffuse breast enlargement and seven patients were presented for post-operative follow-up.

The study took place in El-Demerdash Hospital during the period from October 2018 to April 2019. Cases were referred from General Surgery Departments in El-Demerdash Hospital. All patients were subjected to full history taking, clinical examination in addition to full field digital mammography and ultrasound.

Digital mammography was performed for 20 patients (mediolateral oblique and craniocaudal views), using General Electric Medical Systems, Milwaukee, WI.

Ultrasound was done complementary to mammography in 20 cases. In the other 2 cases who were young ultrasound was done alone.

The study was conducted using "General Electric Medical Systems, Logiq Seven PRO" device with a high frequency probe (5 to 7.5MHZ), scanning was done in all planes (radial, antiradial, longitudinal and transverse).
Mammographic images were inspected and analyzed to detect any presence of masses, architectural deformation, irregular density and calcification. Site, number, margins and density were assessed in all detected masses; however, in microcalcification, shape and distribution were evaluated.

Masses were reevaluated using US focusing on their shapes, orientation, margins, echo pattern (anechoic, hyperechoic, complex, hypoechoic, and isoechoic), lesion boundary (abrupt interface, echogenic halo), presence or absence of acoustic shadowing or enhancement.

Classification of breast lesions was done based on the "Breast Imaging Reporting and Data System (BI-RADS)". Then all patients with BIRADS 3 \& 4 were subjected to further DCEMRI \& MRS examination.

\section{MR imaging protocol:}

Dynamic contrast enhanced MRI was done using high field strength 1.5 Tesla on Signa system (Philips Intera) with help of dedicated double breast coil.

Coronal T1 weighted spin echo sequence was implemented for localization process followed by plain sequences using $\mathrm{T} 1$ weighted fast spin echo sequence ( $\mathrm{TR}=501 \mathrm{msec}$., $\mathrm{TE}=10 \mathrm{msec}$.), in addition to $\mathrm{T} 2$ weighted fast spin echo sequence ( $\mathrm{TR}=$ $4131 \mathrm{mesc}$., $\mathrm{TE}=120 \mathrm{msec}$.) in axial orientation. Respiratory triggering was applied for better resolution.

A bolus of gadolinium dimeglumine (Gd-DTPA) (Magnavist), was injected manually intravenous at a dose of $(0.1 \mathrm{mmol} / \mathrm{kg})$ followed by saline flush to ensure that contrast-enhanced images could be obtained immediately after contrast agent injection. Dynamic T1 WIs then performed using Gradient echo T1 weighted image with fat suppression at the following time points: 1.27 minute, $2.55 \mathrm{~min}$., $4.21 \mathrm{~min} ., 5.47 \mathrm{~min}$ and $7.13 \mathrm{~min}$.

\section{Image post processing on the workstation:}

Post processing image subtraction was taken between the post contrast imaging showing maximum enhancement and pre-contrast images (in the same axial plane), applying the software subtraction function.

A single-voxel water and fat-suppressed generalized breast spectroscopy examination was performed. Proceeding proton MRS, the channel con- 
tralateral to the lesion was turned off. Automated parameter optimization involved frequency and receiver gain adjustment in addition to gradient tuning.

In order to minimize eddy currents and to maximize the water echo signal, localized MRS was first done with water suppression for adjustments of the gradients ("gradient tuning").

Gradient tuning and stability were assured through prelocalizing a Volume of Interest (VOI) in a case. Then localized automatic shimming of the VOI was executed.

A semiautomatic shimming adjustment was done to assure a Full Width at Half Maximum (FWHM). ROI was determined for each DCEMRI-detected lesion and single voxel was applied on the ROI for MR spectroscopy analysis.

Unsuppressed water peak lower than $25 \mathrm{~Hz}$ as a quality parameter of the MR signal.

If FWHM values were higher than $25 \mathrm{~Hz}$, the adjustment procedure was repeated. If FWHM values were still higher than $25 \mathrm{~Hz}$, the quality check was considered unsatisfactory and the MRS examination was interrupted and considered a failure because of technical reasons, such as patient movement or irregular breathing.

Proton MRS spectroscopy was acquired using the following technical parameters: TR/TE, 1500/ $135 ; 128$ acquisitions; spectral width, $1000 \mathrm{~Hz}$; and 1024 data points. The MRS scan time was 3 minutes 18 seconds. In addition, the time for shimming ranged from 3 to 5 minutes according to lesion.

Therefore, the total time to acquire MRS per one lesion, including scan time and shimming, was usually ranged from 6 to 8 minutes. The volume of interest was a rectangular box, positioned by a radiologist has experience in breast MRI.

The positioning of the VOI was performed on the basis of axial, coronal, and sagittal subtraction images. The distribution of VOI was skewed, with a mean $( \pm \mathrm{SD})$ of $2.66 \pm 2.34 \mathrm{~mL}$. Its axes were always parallel to the axial, sagittal, and coronal reference planes. The VOI position and size were chosen to encompass each enhancing lesion, limiting as much as possible the inclusion of nonenhancing gland parenchyma or surrounding fat.

\section{MRI image interpretation:}

Subtraction images were first examined to detect the presence or absence of lesion enhancement.
In case of lesion enhancement the corresponding non subtracted pre-contrast and post contrast images in each time point was viewed together and lesions interpretation took place whether it a focus, mass.

In case of mass enhancement evaluation was carried out as follows: Its shape (regular or irregular). Its border (well defined, ill defined, speculated). Pattern of enhancement (homogenous, heterogeneous), dynamic behavior of the mass with evaluation of the \% of enhancement as well as the shape of time/signal intensity curve (type I, type II or type III) was studied. The value of the choline height peak in the MRS study.

\section{Histopathological methodology:}

20 cases were subjected to routine histopathological examination and eosin stain sections of both the true cut core and the surgical specimen and were examined using the both low and high microscopic power.

All the cases were subjected to immune histochemical study using the ki67, monoclonal antibody to access the ki67 score which reflects the proliferative activity of the tumor cell population which reflects on the grade and the biological behavior of the lesion.

\section{The statistical paragraph in material and methods:}

Data were statistically described in terms of mean \pm Standard Deviation $( \pm S D)$, median and range. Comparison between the study groups was done using one way analysis of variance (ANOVA) test with post-hoc multiple 2-group comparisons. Accuracy was represented using the terms sensitivity, and specificity. Receiver Operator Characteristic (ROC) analysis was used to determine the optimum cut off value for the studied diagnostic markers. $p$-values less than 0.05 was considered statistically significant. All statistical calculations were done using computer program SPSS (Statistical Package for the Social Science; SPSS Inc., Chicago, IL, USA) version 15 for Microsoft Windows.

\section{Statistical analysis:}

Recorded data were analyzed using the statistical package for social sciences, version 20.0 (SPSS Inc., Chicago, Illinois, USA). Quantitative data were expressed as meanv \pm Standard Deviation (SD). Qualitative data were expressed as frequency and percentage. Probability ( $p$-value): $p$-value $<0.05$ was considered significant; $p$-value $<0.001$ was considered as highly significant and $p$-value $>0.05$ was considered insignificant. 


\section{Results}

Table (1): Clinical finding distribution of the study group.

\begin{tabular}{lcc}
\hline Clinical finding & No. & $\%$ \\
\hline Post-operative follow-up & 7 & 35.0 \\
Palpable lump & 6 & 30.0 \\
Diffuse breast enlargement & 4 & 20.0 \\
Nipple discharge & 3 & 15.0 \\
\hline Total & 20 & 100.0 \\
\hline
\end{tabular}

This table shows that the diffuse breast enlargement $4(20.0 \%)$, palpable lump $6(30.0 \%)$, nipple discharge $3(15.0 \%)$ and post-operative follow-up $7(35.0 \%)$ of clinical finding.
Table (2): Diagnosis distribution of the study group.

\begin{tabular}{lcc}
\hline Finding diagnosis & No. & $\%$ \\
\hline Diffuse skin thickening and edema & 6 & 30.0 \\
Recurrent malignant tumor & 5 & 25.0 \\
Fat necrosis & 3 & 15.0 \\
Seroma & 2 & 10.0 \\
Post-operative scar & 2 & 10.0 \\
Normal & 2 & 10.0 \\
\hline
\end{tabular}

This table shows that the fat necrosis $3(15.0 \%)$, seroma $2(10.0 \%)$, recurrent malignant tumor 5 $(25.0 \%)$, diffuse skin thickening and edema 6 $(30.0 \%)$, post-operative scar $2(10.0 \%)$ and normal $2(10.0 \%)$ of finding diagnosis.

Table (3): Relation between find diagnosis and clinical finding distribution of the study group.

\begin{tabular}{lllcccc}
\hline Clinical finding & \multicolumn{1}{c}{$\begin{array}{c}\text { Fat } \\
\text { necrosis }\end{array}$} & \multicolumn{1}{c}{ Seroma } & $\begin{array}{c}\text { Recurrent } \\
\text { malignant tumor }\end{array}$ & $\begin{array}{c}\text { Diffuse skin } \\
\text { thickening and edema }\end{array}$ & $\begin{array}{c}\text { Post-operative } \\
\text { scare }\end{array}$ & Normal \\
\hline Diffuse breast enlargement $(\mathrm{n}=4)$ & $1(33.3 \%)$ & $0(0.0 \%)$ & $0(0.0 \%)$ & $3(50.0 \%)$ & $0(0.0 \%)$ & $0(0.0 \%)$ \\
Palpable lump $(\mathrm{n}=6)$ & $0(0.0 \%)$ & $2(100.0 \%)$ & $4(80.0 \%)$ & $0(0.0 \%)$ & $0(0.0 \%)$ & $0(0.0 \%)$ \\
Nipple discharge $(\mathrm{n}=3)$ & $0(0.0 \%)$ & $0(0.0 \%)$ & $0(0.0 \%)$ & $1(16.7 \%)$ & $1(50.0 \%)$ & $1(50.0 \%)$ \\
Post-operative follow-up $(\mathrm{n}=7)$ & $2(66.7 \%)$ & $0(0.0 \%)$ & $1(20.0 \%)$ & $2(33.3 \%)$ & $1(50.0 \%)$ & $1(50.0 \%)$ \\
\hline Total & $3(100.0 \%)$ & $2(100.0 \%)$ & $5(100.0 \%)$ & $6(100.0 \%)$ & $2(100.0 \%)$ & $2(100.0 \%)$ \\
\hline
\end{tabular}

Table (4): Detection of recurrent malignant tumor distribution of the study group.

\begin{tabular}{lll}
\hline $\begin{array}{l}\text { Detection of recurrent } \\
\text { malignant tumor }\end{array}$ & No. & $\%$ \\
\hline Malignant & 5 & 25.0 \\
Benign & 13 & 65.0 \\
Normal & 2 & 10.0 \\
\hline Total & 20 & 100.0 \\
\hline
\end{tabular}

This table shows that the malignant $(25 \%)$, benign $(65 \%)$ and normal $(10 \%)$ of detection of recurrence malignant tumor.

Table (5): Presence of fat on T1W1 distribution of the study group.

\begin{tabular}{lcc}
\hline $\begin{array}{l}\text { Presence of fat } \\
\text { on T1W1 }\end{array}$ & No. & $\%$ \\
\hline Absent & 11 & 55.0 \\
Present & 9 & 45.0 \\
\hline Total & 20 & 100.0 \\
\hline
\end{tabular}

This table shows that the absent (55\%) and present (45\%) of presence of fat on T $1 \mathrm{~W} 1$.
Table (6): Margin of the lesion distribution of the study group.

\begin{tabular}{lcc}
\hline Margin of the lesion & No. & $\%$ \\
\hline Irregular & 3 & 15.0 \\
Regular & 4 & 20.0 \\
Speculated & 4 & 20.0 \\
\hline
\end{tabular}

This table shows that the irregular $3(15 \%)$, regular $4(20 \%)$ and speculated $4(20 \%)$ of margin of the lesion.

Table (7): Pattern of enhancement distribution of the study group.

\begin{tabular}{lll}
\hline Pattern of enhancement & No. & $\%$ \\
\hline Heterogeneous enhancement & 6 & 30.0 \\
Marginal enhancement & 4 & 20.0 \\
No enhancing lesions & 8 & 40.0 \\
Non-mass like enhancement & 2 & 10.0 \\
\hline Total & 20 & 100.0 \\
\hline
\end{tabular}

This table shows that the heterogeneous enhancement $6(30.0 \%)$; marginal enhancement 4 (20.0\%); no enhancing lesions $8(40.0 \%)$ and nonmass like enhancement $2(10.0 \%)$ of pattern of enhancement. 
Table (8): Relation between detection of recurrent malignant tumor and presence of fat on T1W1 of the study group.

\begin{tabular}{|c|c|c|c|c|c|}
\hline \multirow{2}{*}{$\begin{array}{l}\text { Presence of } \\
\text { fat on } \mathrm{T} 1 \mathrm{~W} 1\end{array}$} & \multicolumn{3}{|c|}{$\begin{array}{l}\text { Detection of } \\
\text { recurrent malignant tumor }\end{array}$} & \multirow{2}{*}{$\chi^{2}$} & \multirow{2}{*}{$\begin{array}{c}p- \\
\text { value }\end{array}$} \\
\hline & Malignant & Benign & Normal & & \\
\hline Absent $(\mathrm{n}=11)$ & $5(100.0 \%)$ & $5(38.5 \%)$ & $1(50.0 \%)$ & 7.683 & $0.036^{*}$ \\
\hline Present $(n=9)$ & $0(0.0 \%)$ & $8(61.5 \%)$ & $1(50.0 \%)$ & & \\
\hline Total & $5(100.0 \%)$ & $13(100.0 \%$ & $2(100.0 \%)$ & & \\
\hline
\end{tabular}

This table shows statistically significant relation between detection of recurrent malignant tumor and presence of fat on $\mathrm{T} 1 \mathrm{~W} 1$ of the study group.

Table (9): Relation between detection of recurrent malignant tumor and margin of the lesion of the study group.

\begin{tabular}{llllll}
\hline \multirow{2}{*}{$\begin{array}{l}\text { Margin of } \\
\text { the lesion }\end{array}$} & \multicolumn{4}{c}{ Detection of } \\
& recurrent malignant tumor & & $\chi^{2}$ & $\begin{array}{c}p \text { - } \\
\text { value }\end{array}$ \\
\cline { 2 - 4 } & Malignant & Benign & Normal & & \\
\hline Irregular (n=3) & $2(40.0 \%)$ & $1(16.7 \%)$ & $0(0.0 \%)$ & 8.286 & $0.028^{*}$ \\
Regular (n=4) & $0(0.0 \%)$ & $4(66.7 \%)$ & $0(0.0 \%)$ & & \\
Speculated (n=4) & $3(60.0 \%)$ & $1(16.7 \%)$ & $0(0.0 \%)$ & & \\
\hline
\end{tabular}

This table shows statistically significant relation between detection of recurrent malignant tumor and margin of the lesion.

Table (10): Relation between detection of recurrent malignant tumor and pattern of enhancement of the study group.

\begin{tabular}{|c|c|c|c|c|c|}
\hline \multirow{2}{*}{$\frac{\text { Pattern of }}{\text { enhancement }}$} & \multicolumn{3}{|c|}{$\begin{array}{l}\text { Detection of recurrent } \\
\text { malignant tumor }\end{array}$} & \multirow[t]{2}{*}{2} & \multirow{2}{*}{$\begin{array}{c}p- \\
\text { value }\end{array}$} \\
\hline & Malignant & Benign & Normal & & \\
\hline $\begin{array}{c}\text { Heterogeneous } \\
\text { enhancement } \\
(n=6)\end{array}$ & $4(80.0 \%)$ & $2(15.4 \%)$ & $0(0.0 \%)$ & 12.538 & $0.041^{*}$ \\
\hline $\begin{array}{l}\text { Marginal } \\
\text { enhancement } \\
(n=4)\end{array}$ & $0(0.0 \%)$ & $4(30.8 \%)$ & $0(0.0 \%)$ & & \\
\hline $\begin{array}{l}\text { No enhancing } \\
\text { lesions }(n=8)\end{array}$ & $0(0.0 \%)$ & $6(46.2 \%)$ & $2(100.0 \%)$ & & \\
\hline $\begin{array}{l}\text { Non-mass like } \\
\text { enhancement } \\
(n=2)\end{array}$ & $1(20.0 \%)$ & $1(7.7 \%)$ & $0(0.0 \%)$ & & \\
\hline Total & $5(100.0 \%)$ & $13(100.0$ & $2(100.0 \%)$ & & \\
\hline
\end{tabular}

This table shows statistically significant relation between detection of recurrent malignant tumor and pattern of enhancement of the study group.
Table (11): Comparison between benign and malignant according to choline peak.

\begin{tabular}{llllll}
\hline $\begin{array}{l}\text { Choline } \\
\text { peak }\end{array}$ & \multicolumn{2}{c}{ Benign Malignant } & Total & $t$-test & $\begin{array}{c}p^{-} \\
\text {value }\end{array}$ \\
\hline Range & $0.023-0.556$ & $0.4-1.2$ & $0.023-1.2$ & 10.523 & $<0.001 * *$ \\
Mean \pm SD & $0.094 \pm$ & $0.770 \pm$ & $0.263 \pm$ & & \\
& 0.031 & 0.286 & 0.338 & & \\
\hline
\end{tabular}

$t$ : Independent Sample $t$-test. $\quad p$-value $<0.001 \mathrm{HS}$.

This table shows statistically significant difference between benign and malignant according to choline peak.

Table (12): Comparison between benign and malignant according to $\mathrm{Ki} 67 \%$.

\begin{tabular}{llllll}
\hline Ki67\% & \multicolumn{1}{l}{ Benign Malignant } & Total & $t$-test & $\underline{p}$-value \\
\hline - Range & $0.285-$ & $5.033-$ & $0.285-$ & 9.636 & $<0.001 * *$ \\
& 6.950 & 20.53 & 20.53 & & \\
- Mean \pm SD & $1.435 \pm$ & $14.155 \pm$ & $4.615 \pm$ & & \\
& 0.902 & 5.834 & 2.278 & & \\
\hline
\end{tabular}

$t$ : Independent Sample $t$-test. $\quad p$-value $<0.001 \mathrm{HS}$.

This table shows statistically significant difference between benign and malignant according to $\mathrm{Ki} 67 \%$.

Table (13): Receiver-Operating Characteristic (ROC) curve for prediction of malignant using the Choline peak and $\mathrm{Ki} 67 \%$.

\begin{tabular}{lcccccc}
\hline Items & Cut_off & Sen. & Spe. & PPV & NPV & Accuracy \\
\hline Choline peak & 0.48 & $100 \%$ & $93.3 \%$ & $83.3 \%$ & $100 \%$ & $98.7 \%$ \\
Ki67\% & 4.31 & $100 \%$ & $86.7 \%$ & $71.4 \%$ & $100 \%$ & $97.3 \%$ \\
\hline
\end{tabular}

Receiver Operating Characteristics (ROC) curve was used to define the best cut off value of:

- Choline peak which was 0.128 , with sensitivity of $100 \%$ specificity of $93.3 \%$ positive predictive value of $83.3 \%$, negative predictive value of $100 \%$ with diagnostic accuracy of $98.7 \%$.

- Ki67\% which was 2.311 , with sensitivity of $100 \%$ specificity of $86.7 \%$ positive predictive value of $71.4 \%$, negative predictive value of $100 \%$ with diagnostic accuracy of $97.3 \%$.

Table (14): Correlation between Choline peak and Ki67\% of the study group.

\begin{tabular}{ccc}
\hline & \multicolumn{2}{c}{ Ki67\% } \\
\cline { 2 - 3 } & $r$ & $p$-value \\
\hline Choline peak & 0.740 & $<0.001 * *$ \\
\hline : Pearson Correlation Coefficient. $* *: p$-value $<0.001 \mathrm{HS}$.
\end{tabular}

The results of choline peak are strongly correlating with the level of $\mathrm{Ki67}$ ( $r=740$ with $p$-value $<0.001)$, the higher the choline the higher the Ki67 the more aggressiveness is the tumor. 


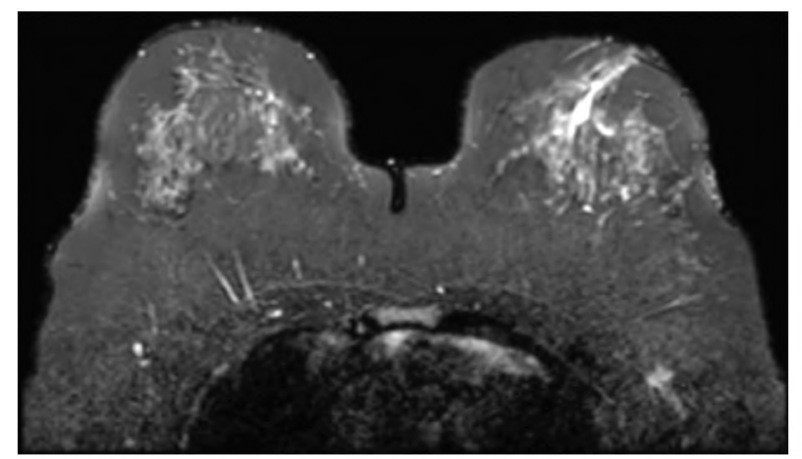

Fig. (1): eSTIR_long TE.

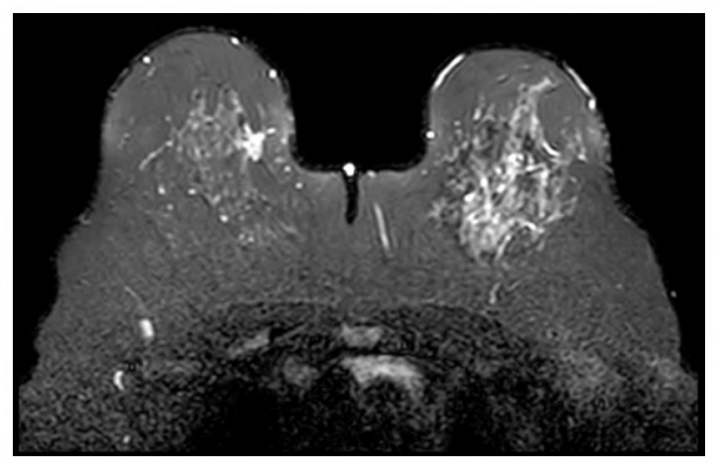

Fig. (3): eSTIR_longTE.

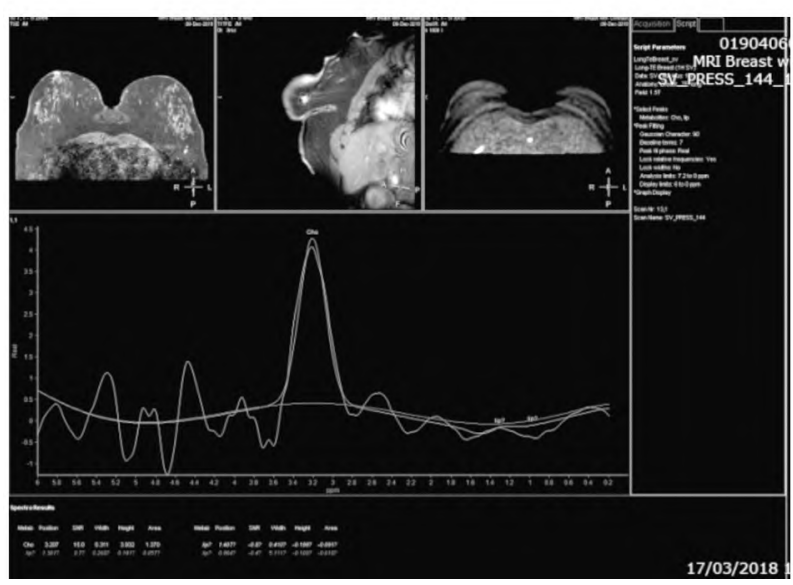

Fig. (5): 49yrs old known case of bilateral multicentric breast cancer for MRI follow-up post chemotherapy.

\section{Discussion}

MR imaging is a very good modality in evaluation of the post-operative breast, as distortion of normal breast tissue may confuse the physical examination and the mammographic assessment of the breast which make difficulties in differentiating between normal postsurgical changes and locally recurrent breast cancer [6] .

MR imaging has been used successfully to differentiate between benign post-operative findings and recurrent breast cancer [4]. The most important factors of MR imaging in differentiation between breast cancer and post-operative changes are the

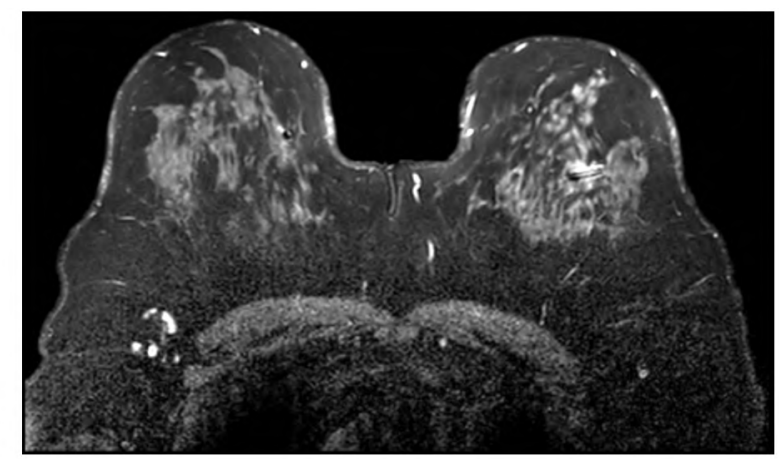

Fig. (2): T1w_TSE + c.

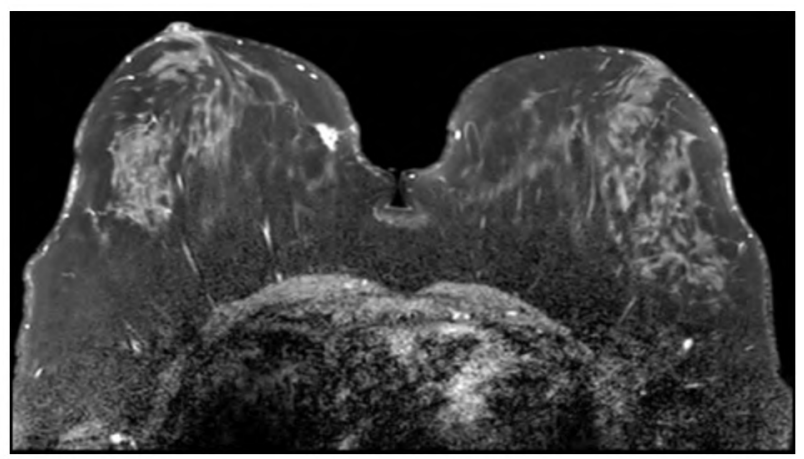

Fig. (4): T1w_TSE + c.

morphology of the lesion and enhancement kinetics following administration of gadolinium contrast material [7]. Breast cancers, whether primary or recurrent, will typically demonstrate early and rapid contrast enhancement with usually delayed washout. Benign post-operative changes, such as fibrosis or fat necrosis, will generally demonstrate more gradual uptake of contrast material [8]

In our study $\mathrm{T} 1 \mathrm{WI}$ played a great role in differentiating between post-operative fat necrosis and tumor recurrence, as post-operative fat necrosis was present in 9 cases from 20 cases with percentage $45 \%$ which were proved pathologically to be of benign nature. The clue for the diagnosis of post-operative fat necrosis is the presence of fat on T 1 WI. This in agreement with [9] who stated that $\mathrm{T} 1 \mathrm{~W} 1$ has a very important role in the assessment of post-operative breast lesions mimicking malignant lesions such as fat necrosis.

Post-operative seromas are common finding following breast surgery. In this study seroma was present in 2 cases from 20 cases with percentage $10 \%$ and they showing well defined margins, hypertense on STIR images and smooth marginal enhancement, this is in agreement with [4]. Which reported that posto-perative seromas have high signal intensity on T2-weighted images and smooth.

In our study, we had 2 patients with non-masslike enhancement with Type I time signal intensity 
curve. Several studies [4] stated that a minimal or small focal area of enhancement or thin linear NonMass-Like Enhancement (NMLE) can be seen for up to 18 months (in some cases even longer) without nodularity or an associated mass and they consider it probably benign and appropriate for 6month MR imaging follow-up.

Petralia (2011) and Drukteinis [4] stated that recurrent malignant lesions showed rapid enhancement following administration of contrast material. Other features including heterogeneous enhancement and speculated margins increase the suspicion of malignancy, comparable with our results; 5 patients proved pathologically to have recurrent breast cancer as their MRI study showed masses with speculated margins and heterogeneous enhancement.

In our study, we found irregular \& speculated margins in $3 \& 4$ mass lesions respectively, 5 of them proved to be malignant, 1 of them were grade I carcinoma, 2 of them were grade II and 2 of them were grade III.

This is comparable with Macura et al., [11] who reported that the marginal morphology of a focal mass is the most predictive feature of the breast MR image interpretation.

In our study we found 1 choline peak in MR spectroscopy of positive results ranging from 0.086 to 0.5 in 15 cases of benign natures while 1 case of grade I carcinoma range about 0.4 while it is ranging from 0.1 to 0.7 to 0.75 in 2 cases of grade II carcinoma also it ranges from 0.8 to 1.2 in 2 cases of grade III carcinoma with a mean of 1.017.

So it is noted that by increasing the grade of malignancy there is relative increase of the mean value of choline, denoting that breast MRS using the Cho peak integral show significant correlation with the grade of the malignancy. On the other hand there is significant difference between benign and malignant lesions according to the choline peak.

$p$-value less than $0.001 * *$ between the benign and malignant lesions.

- Suggested cut off value is assumed when choline value reaches 0.48 .

- Above this value malignancy is highly suggested below it benignity is highly suggested.

- Sensitivity at this level $=100 \%$.

- Specificity at this level $=93.3 \%$.

From the above we can conclude that the results of choline peak are strongly correlating with the level of Ki67, the higher the choline the higher the Ki67 the more aggressiveness is the tumor.

\section{Conclusion:}

Dynamic contrast enhanced MRI and Magnetic resonance spectroscopy are a valuable tools in evaluation of post-operative breast as they have high sensitivity and specificity in differentiation between benign post-operative changes and recurrent malignant tumor. Breast MRI minimizes unnecessary intervention and optimizes diagnosis of recurrence in its early stages.

\section{References}

1- GUTIERREZ R., HORST K.C., DIRBAS F.M. and IKEDA D.M.: Breast imaging following breast conservation therapy. In: Dirbas F.M., Scott C., editors. Breast surgical techniques and interdisciplinary management. USA: Springer; 975-95, 2011.

2- NEAL L., SANDHU N.P., HIEKEN T.J., GLAZEBROOK K.N., BRIDE M.B.M., DILAVERI C.A., WAHNERROEDLER D.L., GHOSH K. and VISSCHER D.W.: Diagnosis and Management of Benign, Atypical and Indeterminate Breast Lesions Detected on Core Needle Biopsy. Mayo Clin. Proc., 89 (4): 536-47, 2014.

3- KAPLAN J.B. and DERSHAW D.D.: Post therapeutic magnetic resonance imaging. In: Morris Elizabith A, Liberman Laura, editors. Breast MRI diagnosis \& intervention. USA: Springer Company, 216-33, 2005.

4- DRUKTEINIS J.S., GOMBOS E.C., RAZA S., CHIKARMANE S.A., et al.: MR imaging assessment of the breast after breast conservation therapy: Distinguishing benign from malignant lesions. Radio. Graphics., 32 (1): 21934, 2012.

5- YI AN Y., KIM S.H. and PARK Y.H.: Response evaluation to neoadjuvant chemotherapy in advanced breast cancer: Comparison of MRI and PET/CT. J. Kor. Soc. Radiol., 1; 71 (2): 89-96, 2014

6- DEVON R.K., ROSEN M.A., MIES C., et al.: Breast reconstruction with a transverse rectus abdominis myocutaneous flap: Spectrum of normal and abnormal MR imaging findings. Radiographics, 24 (5): 1287-99, 2004.

7- OREL S.G. and SCHNALL M.D.: MR imaging of the breast for detection, diagnosis, and staging of breast cancer. Radiology, 220 (1): 13-30, 2001

8- HETTA W.: Role of diffusion weighted images combined with breastMRI in improving the detection and differentiation of breast lesions. Egypt J. Radiol. Nucl. Med., 46 (1): 259-70, 2015.

9- MANSOUR S.M. and BEHAIRY N.: Residual breast cancer or postoperative changes: Can diffusion magnetic resonance imaging solve the case? Egyp. J. Radilo. Nucl. Med., 46 (1): 225-34, 2015.

10- FOURNIER H.O., OLSON L.K., ROCHELLE M., et al.: Accelerated partial breast irradiation and posttreatment imaging evaluation. RadioGraphics, 2011.

11- MACURA K.J., OUWERKERK R., JACOBS M.A. and BLUEMKE D.A.: Patterns of enhancement on breast MR images: Interpretation and imaging pitfalls. Radiographics, 26 (6): 1719-34, 2006 


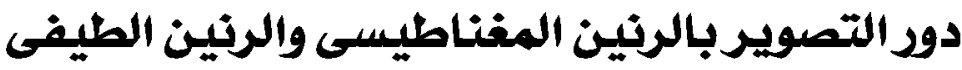

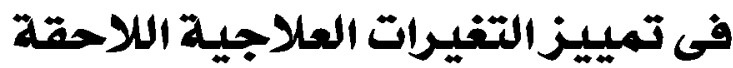

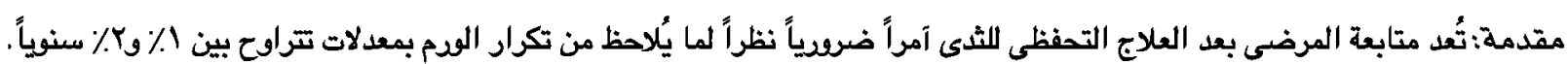

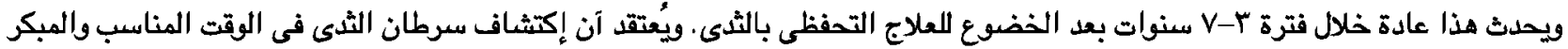
من شآنه آن يحسن ويساعد بشكل كبير على البقاء على المدى الطول الطفل.

الهدف من الدراسة: تقييم التطودات الجديدة فى التصوير بالرنين المغناطيسى والتحليل الطيفى بالرنين المغناطيسى فى تثخيص سرطان الثىى المتكرد بعد الجراحة المحافظة والعلاج الكيميائى والعلاج الإشعاعى وتمييزه عن التغيرات التئين اللاحقة للعلاج.

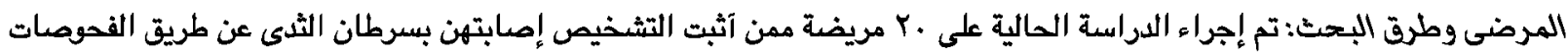

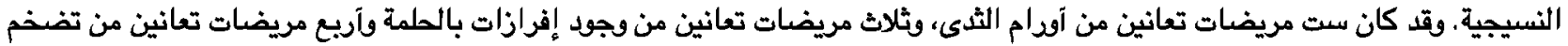

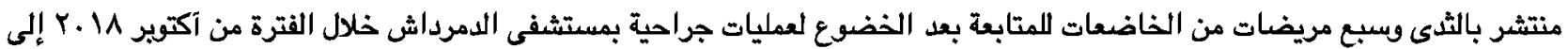

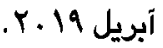

النتائج: تم إكتشاف وجود علاقة إيجابية قوية بين التتائج القصوى للكولين وبين مستوى Ki67، وكلما إرتفع الكولين كلما إرتفع Ki67 كلما زادت الودم.

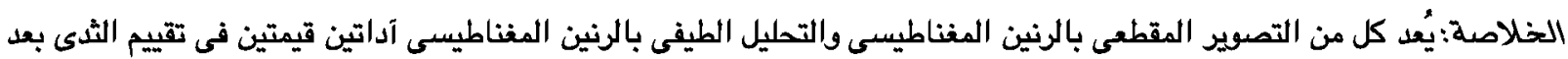

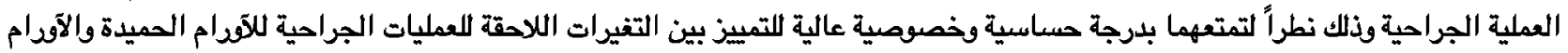

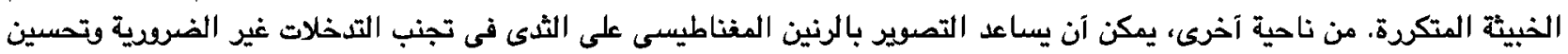
تشخيص الحالات المتكرةة في مراحل مبكرة. 